\section{Building expectations: Imagining family languages policy and heteroglossic social} spaces

Judith Purkarthofer, judith.purkarthofer@iln.uio.no

Center for Multilingualism in Society Across the Lifespan, University of Oslo

\section{Abstract}

\section{Aims and Objectives/Purpose/Research Questions:}

The article examines the language expectations of three couples with different language backgrounds - each expecting their first child. The study addresses three related questions: In what ways are linguistic resources imagined by the future parents? What social spaces and relations do they envision themselves and their child moving in, and how is this relevant for their family language policy?

\section{Design/Methodology/Approach:}

Situated within an ethnographic framework, speaker-centered qualitative methods (language portraits, biographic narratives) are combined with analysis of multimodal tasks to analyze the parents' construction of spaces of interaction, drawing on Lefebvre's triadic concept of the production of space (1991).

\section{Data and Analysis:}

Co-constructed narratives of the three couples were elicited: starting with individual language biographies, the couples then constructed their family's future in the form of visual representations of the spaces that they are about to inhabit. Recordings and pictures of the constructions were analyzed jointly to understand how parents assign relevancy to their language resources, social spaces and family language policies.

\section{Findings/Conclusions:}

The analysis shows how the parents construct the child as a multilingual self in her/his own right, subject to a biography that will develop, and who is influenced but not controlled by the parents. The multimodal data provide a window into the negotiation of language policy between the future parents.

\section{Originality:}

The innovative character of this paper comes from its combination of speaker-centered biographical methods with the interactive construction of three-dimensional future family spaces. Methodologically, this contribution renders theories of the construction of social space relevant for research on family language policy and practices.

\section{Significance/Implications:}

While the study deals with the very specific situation of approaching parenthood, the findings, together with its original methodology and analytical framework, shed light on the construction of family language policy as an on-going process, starting before birth.

\section{Key words}

speaker-centered approach, family language policy, language biographies, social spaces, parental expectations

\section{Introduction}

Family Language Policy (FLP) examines language planning and language choice among family members. This article centers on the development of FLP and the motivations and aspirations of parents before their first child is born. Parents are, beyond their perceived role as caregivers, embedded in public discourses on languages, and they are active participants in superdiverse environments within their local community and in contexts of transnational migration (cf. Crippen \& Brew, 2007; Dagenais \& Berron, 2001; Dong, 2012; Roubeni, De Haene, Keatley, Shah \& Rasmussen, 2015). Their perception of societal beliefs, as well as their biographic experience and abilities, play a part in their decisions to expose children to all or parts of their linguistic repertoire. As King and Fogle (2006, p. 699) show, these processes are 
but decide to introduce a second language to their child.

Situated within an ethnographic framework, this research draws on speaker-centered qualitative methods (language portraits, biographic narratives, see Busch, 2006). This paper examines the negotiation of language ideologies among individuals and groups of speakers, and analyzes social space to gain a broader understanding of how language regimes are realized and perceived in practice. Within the framework of FLP, the concepts and methodology of speaker-centered approaches can be used to further understand families' choices, motivations and the planning and implementation of FLP.

In this article, the focus is on the construction of the child's agency concerning language use, even before the child's birth. Thus, the analysis targets how parents co-construct their unborn child as an actor in their imagined FLP. In the following section, the theoretical connections between speakers' biographical language experiences, language ideologies and language regimes are discussed and the importance of social space for this study is explained. Subsequently, the methodological approach is presented, along with information on participants and data collection. An explanation is provided for how and why language portraits and LEGO ${ }^{\circledR}$ building blocks can be productively used to encourage parents talk about their expectations and motivations. Data from both activities are then presented and analyzed to arrive at some conclusions about parental co-construction of multilingual family spaces, including the role of the (unborn) child in the construction of the FLP.

\section{Multilingual speakers in social spaces}

In talking about families as constructing and inhabiting dynamic systems of meaningmaking, attention needs to be drawn to the positions and imaginations that family members hold as subjects. These experiences can be regarded as lived language experiences of speakers, composed of their individual emotions, their social encounters, their biographies of language learning and use, and their aspirations and ideas about languages. Over time, these experiences form linguistic repertoires (Gumperz, 1964; Busch, 2012), including not only competencies, but all kinds of relations and knowledge drawing on different languages, speech styles, modes of expression and the contexts of their use. The linguistic repertoire changes over the lifespan as it develops according to individuals' needs, ideas and possibilities of participation. Some languages gain more importance over time; some may be forgotten or even lost as they are not used any longer or associated with negative social value. Important biographical events, like becoming a parent, are expected to have an influence on the construction and reevaluation of one's own language biography. Language choices are likely to be negotiated between the parents: as such, aspirations and imaginations occupy an important part of the interviews and activities in the data elicitation methods of this study.

Drawing on Bakhtin's concept of heteroglossia (Busch, 2012), forms of speech and language are taken here as being combined meaningfully to accommodate linguistic and communicative needs in any given time and space. Kramsch (2009, p. 2) introduced the notion of the multilingual self to understand how "[a]s a sign system, language elicits subjective responses in the speakers themselves: emotions, memories, fantasies, projections, identifications. Because it is not only a code but also a meaning-making 
our 'selves'”. These multilingual selves are seen as changing over time, building up experiences to construct one's own positioning as an individual in society. Individual speakers may feel confident or vulnerable in their heteroglossic environments, depending on their resources and strategies, but they are also dependent on the language ideologies and language regimes they encounter. Norton (2013, p. 45) uses the term 'identity' to describe "how a person understands his or her relationship to the world, how that relationship is constructed across time and space, and how the person understands possibilities for the future”. Both Kramsch (2009) and Norton (2013) provide insights into the affective links and imaginations helping or hindering desired participation in (new) language environments.

Language environments are shaped by language ideologies, which encompass beliefs and evaluations of languages and (maybe more importantly) their speakers. Irvine and Gal (2000) described processes of differentiation through ideologies in multilingual contexts. More recently, Pavlenko and Blackledge (2004, p. 3) pointed to the importance of language ideologies, stating that "the fact that languages - and language ideologies - are anything but neutral is especially visible in multilingual societies where some languages and identity options are, in unforgettable Orwellian words, 'more equal than others'”. Within families, language ideologies can motivate parents to push their children towards the use of perceived languages of social success, but they can also drive parental support for the maintenance of family languages in minority or migration contexts. There is little question about the crucial role of family socialization when it comes to language transmission, maintenance, or shift (Lanza, 2007; Hinton, 2013), and FLP proves an especially interesting perspective to understanding choices by multilingual parents (King \& Fogle, 2006; Piller 2002) or parental choices in situations of migration (Curdt-Christiansen, 2009). Despite the focus on parents in these works, the family in FLP is generally seen as a dynamic system, including both adults and children as actors with their own agency (Gafaranga, 2010; Schwartz \& Verschik, 2013). This aligns with the emerging focus on children as actors 'in their own right' (Mayall, 2002). As parents and children move through social and geographical spaces, they encounter different language ideologies and different language regimes.

Language regimes are seen as the set of manifest, implicit and explicit norms and regulations of language use in any given social space (see contributions in Kroskrity, 2000). They include individuals' decisions as well as nationwide language policies and contradictory language regimes might exist within the same space. Language regimes in family spaces are of course influenced by FLP, but while the focus of FLP is on a smaller number of social actors, societal language ideologies and language regimes are negotiated among a greater number of speakers, bound together by long-term connections but also short-term interactions.

Conducting research in a specific, localized environment, and gaining situated knowledge about spatial and language practices, allows for in-depth insights into complex systems (England, 2008). Space, seen as a relevant dimension for the analysis of social interaction, is understood as a documentation of social forces, dynamically constructed, and both historically grounded and performed over time (Massey, 2005; Tuan 1977).

Lefebvre's (1991) triadic framework of the production of space, which is the main framework of analysis, focuses on the construction of social spaces, as they are negotiated between actors with their discursive power, material constraints, and spatial 
practices. Examples of the ways that his work has provided theoretical grounding to research on multilingualism and space include, among others, Ma's research on translocality in Hong Kong youth culture (2002) and Busch's research on the use of diacritics as a spatial marker in a minority language context (2013). Lefebvre distinguishes three aspects of the production of social space: spatial practices, which consist of a multitude of (almost invisible) actions, and they cannot be accessed as data directly. Through language use and everyday actions, spatial practices contribute to the construction of spaces, and make them recognizable to speakers. Participants can make use of spatial representations to express their intentions and the 'rulings' of their surroundings (planned space). In the building exercise in this study, spatial representations are used to express intended policies and to distinguish spaces as they ought to be. At the same time, spaces of representation (lived space) are present, specifically in the form of intervening experiences and actions. Space of representation is what Lefebvre names 'perceived space', the space of inhabitants and users. When talking about their future, parents used these spaces to negotiate potential interventions and the unexpected.

\section{Methodology and Multimodal Data}

Using an innovative methodological framework, this research links bodily and emotional experience to social constructions and representations, and focuses on the motivations and interpretations of the parents. Conducting research on lived language experience can be done through different modes, but it always deals with individual and societal experience: asking speakers to reflect on and talk about their language biographies, specific parts of their linguistic repertoire or learning experiences that may have accompanied them for an extended period of time. Rather than guiding participants to discuss FLP directly, their understandings and explanations are interpreted through engaging them in discussion and creative manual activities. Categories are introduced by the research participants themselves, as they draw on their knowledge and evaluations to construct their future language goals. For the analysis, two sets of data were used, and the methodological background and procedure for each is described below.

\subsection{Collecting biographical data}

Participants were asked to use an empty silhouette of a human shape to draw with colored pens all the languages that were/are/will be relevant to them. This task has been developed as part of language biographical research (Busch, 2006; 2012), both with children and adults. Language portraits cannot be analyzed independently from each speaker's descriptions and explanations, but they are used as a starting point for interviews, enabling participants to think about their languages in a different way and through the visual cues to foster understanding between participants and researchers. Busch's (2006) work on biographical methodology, bodily experience and interpretations of language experience shows how a set of methods is needed to access meaning and to offer insights into the meaning-making of speakers. The multimodal methods employed in this study fulfill this purpose.

The couples in this study were asked to draw individual language portraits and then to talk about their own language biographies, their imaginings and aspirations for themselves and their child. In the course of the conversation, they were also asked about intended language use and policy. These first parts of the interviews were audiorecorded, transcribed and analyzed to identify individual's language biographies, and the language decisions and experiences the parents considered meaningful for their own 
parenting style.

\subsection{Eliciting representations of social spaces}

Language biographical methods tend to focus on individuals' accounts and while most participants will start talking together about their expectations, it is productive to use a complementary research method that demands a higher degree of negotiation and intersubjective construction. To capture intended and imagined FLP as they are about to happen in a social space, the second part of the meeting consisted of the building of a joint future - taking a closer look at the social spaces and encounters the families were planning for themselves and their child. Thus, the parents were provided with LEGO ${ }^{\circledR}$ building blocks (of different shapes and colors, including plants, human figures and some animals) and asked to use them to express the spaces they found relevant, now and in the imagined future. Gauntlett (2007) used a comparable approach in media studies, asking for expressions of identity through building with LEGO ${ }^{\circledR}$ blocks. However, while his participants were asked to build their own identities, the focus in this study is on the joint character of this visual and verbal method. The playful character, the rediscovering of childhood memories linked to these building blocks, and the joint endeavor made this approach appealing, with all participants starting to work on their constructions without hesitation. After a short period of uninterrupted building, participants were asked to explain their construction, which led to interesting negotiations, possible resignifications, and subsequent shifts in meaning throughout the conversation. Through this novel task, the parents were presented with the necessity to (re)formulate points of view they perceived as shared, which fostered talking about 'everyday life' from a new perspective. Each couple was recorded, with audio and video recording, and pictures of the buildings and arrangements were taken. These data were transcribed and analyzed for spatial representations and spaces of representations. The findings from this exercise were brought together with the professed intentions and evaluations from the biographical descriptions and interpretations.

\subsection{Participants}

The participants were three heterosexual couples: two expecting their first child within two months, and the child of the third couple was born four weeks prior to the interview. Participants were between 28 and 45 years of age, and four of them had completed university education. At the time of the interview, the three couples were each living together - in Vienna, Western Hungary and South Tyrol/Italy respectively. While two of the couples have different first languages (English/German, German/Italian), the couple in Hungary is German-speaking and living in a de facto bilingual border region (see Table 1). English plays an important role for all participants as a lingua franca in work contexts but also for personal relations. Italian is one of the main languages in South Tyrol, relevant for both family and work contexts. Hungarian, Spanish and Turkish were connected with biographic events for some of the participants but carried less importance at the moment of the interviews. All but one of the participants had prio experience of living abroad.

Table 1. Reported background information.

\begin{tabular}{|l|l|l|l|l|l|l|l|}
\cline { 2 - 8 } \multicolumn{1}{c|}{} & \multicolumn{2}{l|}{ Couple 1 (Vienna) } & \multicolumn{2}{l|}{ Couple 2 (Hungary) } & \multicolumn{2}{l|}{ Couple 3 (South Tyrol) } \\
\cline { 2 - 8 } \multicolumn{1}{l|}{} & & & & Friedrich & Susanna & \\
\cline { 2 - 8 } & Ilse (I) & Jack (J) & Pia (P) & (F) & (S) & Adriano (A) \\
\hline First language & German & English & German & German & German & Italian \\
\hline Languages in the & & & & & & \\
relationship & E, G & E, G & G & G & E, I & E, I \\
\hline Languages with friends & G, E & E, G, T & G, S, E & G, E, H & G, I, E & I, E \\
\hline Languages of the & & & & & & \\
environment & G & G & H, G & H, G & G, I & G, I \\
\hline Languages of work & G & G, E, T & G, E, H & G, H, E & G, E & I, E, G \\
\hline Languages of the & G, E & E, G & G & G & G, E & E, G \\
\hline
\end{tabular}


interview

Languages: E: English, G: German, H: Hungarian, I: Italian, S: Spanish, T: Turkish.

The transcripts below come from interviews, which lasted between two and four hours per couple. German and English were used during the interviews: the excerpts are given in the original language and German transcripts are translated into English. Transcription conventions can be found in the appendix at the end of the article.

\section{Language portraits and parents' language experiences}

As the focus in this article is on the future FLP, excerpts from the interviews of the three couples are presented to show how the parents construct their expectations and negotiate the languages they consider relevant for their child. The analysis of the interviews and portraits followed the reasoning of the speaker and aimed to provide an understanding of how personal experiences and language ideologies shape the linguistic repertoire of the speaker and how this repertoire is imagined to develop in the future. Drawing on experiences from their own biographies, parents build their FLP to accommodate expectations and build relations to social spaces and language ideologies.

Excerpt 1, by Ilse (from Vienna, see Table 1), and the matching language portrait are illustrative of the data. While the silhouette is used in all interviews, it needs to be noted that all portraits employ different visual means to depict languages (patterns, colors) or forms of speech and expression (such as body language). Ilse talks about the general composition of her portrait and gives some of her reasons for it in the opening part of the interview.
Illustration 1: Language portrait Ilse

Excerpt 1

Ilse: Und das in der Mitte is also das Lilane ist Englisch und das Grüne wieder Deutsch. Und i[ch] habs Gefühl so, das ist beides recht recht zentral, natürlich ist Deutsch jetzt a[uch]/ eben hab i[ch] bei den Händen einzeichnet, weils einfach trotzdem noch mehr die Sprache is, mit der i[ch] wirklich jeden Tag einfach umgeh und tu mit anderen Leuten. Aber ja, Englisch is a[uch] schon sehr sehr zentral eigentlich. Es vermischt sich immer mehr, hab ich das Gefühl.

Ilse (translated): And this in the middle/ the purple is English and the green part is German again. My feeling is that both are rather central, of course, German, I used for the hands, because it is simply more of a language of every day and with other people, but yes, English is very very central. It becomes more mixed all the time, that's my feeling.

This small excerpt gives a glimpse of the complex linguistic repertoire involved, but the use of bodily experience (the German language as a tool 'in the hands') already points to the importance attributed to the two languages that Ilse perceives as central. At the same time, she uses the portrait to include the outer world and to bring in the status of German as the 'everyday language' outside of the couple's relationship. In the final utterance of this excerpt, Ilse speaks about her feeling of the increasing mixture or coexistence of German and English in her life and how this reflects the language use among the parents who reportedly used English and German almost interchangeably while Ilse talks about her preference for English as the language of emotions and her relationship with her partner. The centrality of both German and English is made visible through the drawn connection between head, heart and womb: expressed in both green and purple, this connection seems to point to the unborn baby, even if the future child is not mentioned explicitly in the initial description of the portrait. Through the connection 
of the verbal utterance and the drawing, languages are put in relation to one another.

The feeling of mixing is thus in Ilse's excerpt illustrated through the rather ordered balance of two languages - a potential indicator for a balanced feeling toward this language situation.

The second couple, Pia and Friedrich, are German speakers in a German and Hungarian-speaking environment. They both started to learn Hungarian a few years prior to the interview. As an outcome of their learning experiences, which they evaluate as not being very successful, they favor the early acquisition of more than one language, as Pia states in Excerpt 2.

Excerpt 2

Pia: Wenn i jetzt Ungarisch lern, denk ich mir, wär/ schön wärs gewesn, wenn ichs als Kind schon glernt hätt. aber i bin in [einem anderen Teil Österreichs] aufgewachsen, da wärs mir ned[nicht] eingefallen/

Pia (translated): When I am learning Hungarian now, I am thinking, it would have been nice, if I had learned it as a child. But I grew up in [another part of Austria], it would have never occurred to me/

Pia draws on her struggle to acquire Hungarian to imagine an easier learning experience for her child, but in this excerpt, she also draws on biographic reasons for her own monolingual upbringing. Pia's portrait features Hungarian as a 'cover' around the body silhouette, which can be interpreted as relatively distant, yet unavoidable. However, since Pia's and Friedrich's environment changed, their language experiences and expectations changed as well. While their family language is German, they do expect their child to experience more than one language, as can be noted in Excerpt 3.

Excerpt 3

Friedrich: Also wir san[sind] momentan deutsch, höchstens das Kind kommt mit Freunden [heim], dann vielleicht a bissl ungarisch

Friedrich (translated): So, we are German at the moment [at home/in the family], only if the child comes [home] with friends, then maybe [there is] a little Hungarian.

The language choice in this excerpt is explicitly linked to the parents ('we'), but extends to the family home or even family domain. The child is positioned as the person transcending this German-language domain and bringing in not only new friends but another language as well. The construction of home as a central element in the narrative as well as the constructed family spaces will be dealt with in more detail in the second part of the analysis, as this relates to the perception of social spaces.

Susanna and Adriano, the third couple, are planning on transmitting both German and Italian to their child, as these are the languages of both parents. But, as we can see in Excerpt 4, they expect their child's language choices to be dependent on the environment

Excerpt 4

Susanna: Ich glaube wenn es schon so/ und wenn er dann lieber Italienisch spricht, dann soll er das/ich hab da kein Problem. Ich denk mir nur, er soll auch meine Sprache kennen und ich glaub das ist ein sehr großer Vorteil für ihn wenn er einfach zwei Sprachen/ auch in zwei verschiedenen/ ähm also eine germanische und eine romanische Sprache/ also zwei Sprachgruppen auch noch. Und dann, was ich gesehen hab, sehr viel seine Freund, obs sie eher eine italienische oder deutsche Gruppe ist/ wenn wir in Südtirol sind, kann das ganz hart mit der Zeit wieder wechseln. Was ich halt von Freunden beobachtet hab.

Susanna (translated): and when he then prefers to speak Italian, then he should do that, I don't have a problem with that, I am just thinking he should also know [master] my language and I think that this is a very big advantage, when he simply knows [masters] two languages, also in two different, so one Romance and one Germanic language, simply . . . and then, what I saw, his friends will play a big role, if they are part of a more Italian or German group, if we are in South Tyrol, that can in any case change 
again over time. That's what I've seen with friends.

Susanna brings different strands into her reasoning here: she first starts with the possibility of choice for the child, followed by her personal wish to be able to transmit her language (German). Her next thought refers to a prominent language ideology of related (and thus closer) languages: one language will pave the way for the (unproblematic) acquisition of further related languages and the ability to access languages of different language families (Germanic and Romance) will present the child with an advantage in life. Given the ideological nature of this claim, no further explanation needs to be given, as she can expect it to be shared among her interlocutors. As for spatial representations, the advantage of different languages can be attributed to representational spaces (of the planned future), whereas the last idea, drawing on personal experience with Susanna's friends, brings in spaces of representation, complete with their lived (and at times incoherent) experiences. The preference for languages is in this last part linked to social groups: the language of friends is - drawing on Susanna's experience - very important and will influence language preferences.

Later in the same interview, Adriano comes back to the same question, speaking about the child's choices between German, Italian or other languages. Without referring to what Susanna had said earlier, he comes to a similar conclusion in Excerpt 5.

Excerpt 5

A: (original in English) for the future of [the baby], I don't know, (..) at the end, it's his choice, his sense, I mean in the end, language is something on the inside, something that is/ as I told you before, is a form of expression. Maybe he decides to express himself in German, maybe he decides to study in German.

Adriano presents language, and the choice of language, here as a means of expression and as such, he constructs a space of representation, inhabited by his child. He describes language as situated inside the speaker and speaks from a position of choice. Choosing a means of expression might also lead to further biographical decisions (i.e. studies in German). While both interviewees are generally positive about all languages in the interview, only German and Italian are mentioned when speaking about the future of the child. We can imagine that this child will learn two to three languages if exposed to European schools; however, the emotional weight can be ascribed to the two languages of the parents.

Although Excerpts 4 and 5 are not produced consecutively, we see both parents constructing the possibility that the child will prefer the other's language (i.e. not the first language of the speaking parent). This could be seen as a form of accommodation to the partner's language: through acknowledging the important role of the second language in the family, and the construction of the possible maintenance of this language (including the non-maintenance of the parent's own first language). Drawing on two aspects of Lefebvre's triad, as explained earlier in this article, this can be interpreted as spatial representations, where bilingual language acquisition is planned and aimed for, at the same time as attention is brought to potential spaces of representation, which need not follow the plans but might hold surprising ('lived') experiences for parents and children.

Throughout these excerpts, we can see connections between the parents' own biographical language experiences and their expectations for the child. In all three cases, the language(s) of the parents are considered important and will, according to the parents' intentions, be passed on to the child. To rephrase the parents' idea of FLP, they will start using their languages with the child and will in this way ensure the opportunity 
for the child to learn the language(s). All couples can think of and present further language support in the form of babysitters, kindergartens and schools to enhance language learning. As noted above, social networks are also considered very relevant in determining questions of language use. The fortunate situation, that of both partners understanding both languages, is mentioned several times in the interviews. The parents' choices about transmitting their languages are hence linked to a feeling of capability in doing so and their desire to be a good source of the language for the child.

In summary, from the parents' perspectives, initially it is the parents' choice of language(s) - in the sense of setting the scene. Individual language experiences and language ideologies inform the parents' decisions and their planning, but the possibility of the child's making his or her own decisions is mentioned in all of the interviews. The child is, even before being born, already considered a speaker in his or her own right, and child agency is thus expected. In general, the parents show openness towards their child's imagined choices and they state (through different examples) that once the child can make independent decisions, they will accept those decisions, hence constructing the family language policy as being open to negotiations.

\section{Language regimes and future social spaces}

References to the parents' language experiences and intentions as well as their openness to the negotiation of FLPs are present in the interview data. In the second step of data collection, each couple was asked to build their future social spaces together by means of small LEGO ${ }^{\circ}$ building blocks. This analysis reveals how the parents co-construct (potential) social spaces and talk about their expectations regarding language regimes, and the use of Lefebvre's triadic conception of spatial practices, representations of space and spaces of representation provide an analytical tool to talk about the construction of representations of language regimes, closely linked to FLP, with the opportunity to take several layers of meaning-making into account.

The rich multimodal data allow us to look at several interesting aspects of the data for the analysis; however, expressions of future family spaces and the place of the unborn child are focus areas. In line with Lefebvre, these constructions are considered to be representational spaces, as the parents speak about the perceived (and imagined) spaces the families (intend to) inhabit. Lefebvre (1991, p. 42) observed that "representational space is alive: it speaks. It has an affective kernel or centre: Ego, bed, bedroom, dwelling, house.”

The affective kernel as a common starting point is evident throughout the data. The construction moves along a center-periphery axis and each comment about the LEGO ${ }^{\circledR}$ construction starts with the parents (and child), thus moving from the perceived center to more peripheral spaces. This is apparent among all the couples. Also Adriano starts with the most central part, and the terms used evoke different ideas, such as green, most important, our part, our life. The social spaces are constructed in this exercise with reference to persons, but also to the environment (spatial aspect) and life (temporal aspect). These are framed already here in relation to the environment, with the small size of the house being contrasted with its openness, again both socially (to everyone) and spatially (to each side).

Illustration 1: Construction using LEGO ${ }^{\circledR}$ blocks (Susanna and Adriano, Couple 3)

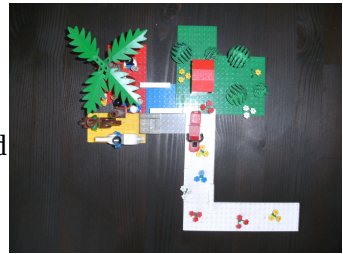


In order to clearly illustrate the importance of space in the couples' discourse, Susanna and Adriano's construction will be discussed in more detail. The different parts can be seen in Illustration 2 (the colors refer to the ground colors, clockwise from top). The green part (top right) is termed family space, linked to the couple and the child. The white part below is ascribed to the future, complete with a motor scooter and flowers in different colors. The small gray part is considered work area (lower center). The yellow part (lower left) is filled with two horsemen, symbolic for the two extended families. The red part (upper left, with the palm tree) is the area of friends, from all around Europe. The small blue part is described as a lake/river, and also as a bridge.

The social spaces are not associated with specific languages; instead Susanna and Adriano use flowers (distributed mainly on the green and white parts to the right in the illustration) to represent languages, as Adriano explains. While the flowers can be read as a specific symbol, their distribution gives the impression of multilingual spaces and none of the social spaces the interlocutors talk about is described as belonging to one language or another. Adriano speaks about representation in concrete or abstract terms and he reasons that the absence of human figures for the couple and child expresses a state of openness. The circular arrangement of the social spaces allows, in his description, equal access to all parts of the construction.

\section{Excerpt 6}

Adriano: in fact, from our reality,

The most important is our future

we haven't put any any small human being

Is a way to escape as well. There are plenty of

that represents Susanna or me or [child]. It means languages as well. Is white, because has to be

that we are open to many things

written,

all around. [points at house with green area]

colored areas]

[points at other areas where LEGO $₫$ figures are] [shows where the white area starts and directs to it]

[shows the thresholds of the green area to other

In the last part of this sequence, the notion of most important part is taken up, and is attributed to the white part, named the future. The possibility of diverging language paths is framed in a (relatively extensive) shared construction and mirrors in a way the earlier sequences from the interview, where language choice was considered an open question for the child. Interestingly, the future paths are also considered open for the parents, both in their joint absence as figures and in their belonging to the area where plenty of languages are possible. With regards to Lefebvre's triad once again, a focus on spatial representations (the planned) as well as potential spaces of representation (the lived) is also visible here. At a later point during the comments and discussion of the building activity, the topic of future plans is brought up again. This time the child's future is mentioned in relation to the extended families: both parents expect these relationships to intensify with the newborn child.

Given the references between the construction and the social spaces that are represented, a back-and-forth movement is noted: Adriano uses the building blocks to speak about his perceived reality (spaces of representation) but he also refers to qualities of the construction (i.e. the possibility to move parts) and uses them to draw conclusions about his reality.

When the couples speak about their constructions and when looking at the actual constructions, we see that parents use visual means to emphasize and negotiate movement between social spaces and languages. The methodology employed allows us 
to isolate strategies employed to link language ideologies and family language policies. Rebuilding / rearranging, resignification and symbols of mobility are used in the dynamic construction of family spaces.

The first strategy that is used can be named rebuilding or rearranging parts of the LEGO ${ }^{\circledR}$ blocks. This is done while describing parts of the arrangement and is often used to present possible developments or outcomes to the partner. One example in the interview is in Excerpt 6, when Adriano shifts parts of the white plates ('the future') to change directions. The plate is used as a temporary image, reformulated (and rearranged on the material level) - this momentary expression allows for comments by the partner, but also allows for continuation. Moving parts of the construction allows the parents to negotiate with one another possible future scenarios. The nature of this multimodal task of course facilitates these forms of expression and through the video recordings, the precise movements and developments, and building and rebuilding can be analyzed.

A second strategy can be called resignification or shift of meaning: parts of the construction that were first associated with one idea are revisited to explore other nuances of meaning. One example in Susanna and Adriano's construction concerns the yellow area, described as the area of the extended families. The figures representing family members are riding horses, which the couple described as a reference to the clanlike structure of families. Of course, this might also be an instance of playfulness related to the building activity. Later in the interview, these same horses are used to express the families' ability to move very quickly to where they are needed. Resignifications occur repeatedly in the comments on the constructions and the dialogic nature of the methods invites the expression of several possible readings. As can be seen with the horses but also in the talk about the potentiality of different arrangements of the areas, these resignifications indicate what Massey (2005) describes as multiplicity of stories inherent in social space. Through the playful nature of the method, multiplicity can be addressed and the spatial representations can be challenged by lived experience. The shift in meaning and the extension of meaning to different qualities of objects can be read as local and in a way ad-hoc forms of re-semiotization (Iedema, 2003).

A third strategy deals with engaging symbols of mobility that are used in the constructions: Various means of transportation (cars, boats, planes) are used to demonstrate moving between different spaces. In the case of the family horses, the metaphor stands for a connection between social spaces (as members of the extended families themselves are situated in very different spaces) but in other constructions, cars and planes are also used to connect two specific places (i.e. the grandparents' home and the family home). At times, these means of transportation might also connect two social spaces like country of origin and host country, but this category was not used in any of the discussed interviews. Symbols of mobility, like the motor scooter in Susanna and Adriano's white area of the future (see Illustration 2), allow the expression of connections that go beyond verbal utterances: the scooter is used by Adriano to indicate traveling to the future, thus using an imagined spatial-temporal vector. In this sense, the common means of transportation is used in resignification and becomes a means of projection. A means of transportation is used to express the mobility of the speakers and the linking of different social spaces, thus constructing another layer of (everyday) mobility and the possibility of movement.

Both language portraits and the building of language spaces do not give us insights into the actual language practices of speakers. Nonetheless, these activities provide us with a means to render language practices, ideologies and regimes of languages topics of a 
conversation. The visual data, as it is analyzed in close connection with the spoken data, point to interesting sequences in the conversation, in particular as moments of negotiation are salient in the rebuilding, resignification or changes in the drawing/construction.

\section{Conclusion}

Future language practices and expectations are of interest to us as researchers but as well to the interviewed parents in their multilingual contexts. The combined qualitative data reveal, on the one hand, the meaning of language experiences and their relevance for individuals and families. On the other hand, this combination of data illuminates the construction of FLP and the couples' negotiation over time.

Language experiences are linked to individual linguistic repertoires and built through biographical and environmental trajectories. The multilingual subject, positioned in a complex set of connections, has agency to change environments and language practices, but is also affected by discourses and personal experiences. Languages and language use are linked to emotions, memories and fantasies (cf. Kramsch, 2009) and dependence on prior experiences leads the parents to conclusions concerning their future life and, by extension, the life of their child.

What we can conclude from the interviews is that parents are engaged in the collaborative construction of a future linguistic repertoire for the child, where the languages of the parents are important, but where possible choices for the child are also developed, including the involvement of friends and yet undecided environments. All of the parents stress the importance of staying open for new possibilities, allowing the child freedom to express him/herself, even to choose a language that is not the language of either parent. In the initial interviews, the first part of the data, we see the notion of possibility and the same notion is also reframed in the second activity, the building of future language spaces. All families insist that a large part of their family future consists of fluid, undecided, empty, inclusive spaces - considered as a freedom and not as a threat. The construction of openness by the parents is highly likely to be linked to their own experience of mobility, of successfully changing their surroundings (in terms of both language use and countries of residence), and their experience of perceiving themselves as taking charge of their own biography. Choices include temporal and spatial aspects, linked to the biographies and trajectories of the parents, and projected onto the life and movements of the child. This perception of spaces of possibilities is linked to the social status, the educational background and the prior life experiences of the parents. Nonetheless the discourses of linguistic capital, and of the value of languages, take a less prominent role than in the findings of other studies (e.g. King \& Fogle, 2006; Curdt-Christiansen, 2009).

In general, the parents show openness towards their child's imagined choices and they state (through different examples) that once the child can make independent decisions, they will accept those decisions. In doing so, they are constructing the FLP as one that is open to negotiations. Looking at FLP, we can understand through these data the changing nature of such policies. This gives us ideas about multilingual realities, in which decisions for certain family language policies, one-parent one-language strategy or others, might be constantly reevaluated in order to suit the changing needs and ideas of family members. Drawing on their own experiences of mobility and the appropriation of languages, parents link these to their expectations for their family language policies.

With regard to the construction and representation of FLP in the interviews, Lefebvre's 
distinction between spatial representations (as planned) and representational spaces (as perceived) becomes very relevant. Parents distinguish between both, when they talk about what they envision for their families or when they speak about what might happen. Negotiation occurs while the parents are talking and trying to find the best place to put the future selves of parents and child. The parents are connected to spatial representations, as they express their awareness of their role in designing policy.

However, through the repeated changing of positions, the parents seem to express a related openness toward their future, in bringing in what Lefebvre considers the lived experiences (even when they are not lived yet). All couples used the building activity to present each other (and the researchers) with alternative scenarios, some very specific, some playfully, some to be avoided, and some as starting points for further developments. What can be seen in all of the constructions is how the participants negotiate borders and limitations of social spaces, some in terms of language borders but others in terms of accessibility of languages, distance and closeness, and resources to overcome (social) distances.

Parents link spatial representations to their own biographies, but with regard to the upbringing of their child, they are very aware of the lived and planned. This is particularly visible when talking about experiences of language learning (and here again, particularly when feelings of shortcomings occur). Another interpretation of lived experience can be found in the ability that develops in people interacting with languages, that is, they do not learn languages in a strict sense but acquire knowledge or experience through 'having them around'. When parents expect languages to become part of their family life (or their child's life), through migration or new social contacts, they might not yet have developed any competence in the language(s), yet they start to position themselves (even hypothetically) vis-à-vis the language(s) and may incorporate them into their construction of future social spaces. In this sense, we can observe a connection between representations of space and the representational spaces that Lefebvre described and the necessary role of the subject, "in whom lived, perceived and conceived (known) come together within a spatial practice” (Lefebvre, 1991, p. 230). The multilingual subject, whose experiences Kramsch (2009) highlights, is thus constantly planning policy and living (in) spaces of representation, a trajectory that can be followed through longitudinal studies. Understanding the planning and perception of social spaces and language helps to explain parents' feelings of success or failure in raising children multilingually, and links research on family language policy to research on multilingualism in society.

\section{Acknowledgements:}

I am very grateful to all of the couples who shared their thoughts and participated in this research and I want to thank my former colleague Jan Mossakowski who contributed to the idea and data collection. I also want to thank the editors and reviewers for their feedback throughout the process and I am grateful for their detailed comments.

\section{Funding:}

The writing of this paper was supported by the Research Council of Norway through its Centres of Excellence funding scheme, project number 223265 (MultiLing) and 240725 (MultiFam).

\section{Notes:}

Transcription conventions

The spelling of the transcripts has been slightly corrected for easier reading. Transcripts are given in the original languages (German or English) and translated into English by 
the author.

$$
\begin{array}{ll}
/ & \text { Interruption, followed by reformulation } \\
, & \text { Brief pause } \\
{[\ldots]} & \text { Description, Comment of the author }
\end{array}
$$

\section{References}

Busch, B. (2006). Language biographies - approaches to multilingualism in education and linguistic research. In B. Busch, A. Jardine \& A. Tjoutuku (Eds.), Language biographies for multilingual learning (pp. 5-18). Cape Town, ZA: PRAESA.

Busch, B. (2012). The linguistic repertoire revisited. Applied Linguistics, 33(5), 503523.

Busch, B. (2013). The career of a diacritical sign: Language in spatial representations and representational spaces. In S. Pietikäinen \& H. Kelly-Holmes (Eds.), Multilingualism and the periphery. (pp. 199-221). Oxford, UK: Oxford University Press.

Crippen, C. \& Brew, L. (2007). Intercultural parenting and the transcultural family: A literature review. The Family Journal: Counseling and Therapy for Couples and Families, 15(2), 107-115.

Curdt-Christiansen, X. L. (2009). Invisible and visible language planning: Ideological factors in the family language policy of Chinese immigrant families in Quebec. Language Policy, 8(4), 351-375.

Dagenais, D. \& Berron, C. (2001). Promoting multilingualism through French immersion and language maintenance in three immigrant families. Language, Culture and Curriculum, 14(2), 142-155.

Dong, J. (2012). When modern public space encounters postmodern migration: Abnormality and the making of migrant identities. Sociolingusitic Studies, 6(2), 239-
257.

England, K. (2008). Caregivers, the local-global, and the geographies of responsibility. In P. Moss \& K. Al-Hindi Falconer (Eds.), Feminisms in geography: Rethinking space, place, and knowledge (pp. 199-206). Lanham, Maryland, Rowman \& Littlefield.

Gafaranga, J. (2010). Medium request: Talking language shift into being. Language in Society, 39(2), 118-135.

Gauntlett, D. (2007). Creative explorations. New approaches to identities and audiences. London, UK: Routledge.

Gumperz, J. J. (1964). Linguistic and social interaction in two communities. American Anthropologist, 66/6(2), 137-153.

Hinton, L. (2013). Bringing our languages home: Language revitalization for families. Berkeley, CA: Heyday.

Iedema, R. (2003). Multimodality, resemiotization: extending the analysis of discourse as multi-semiotic practice. Visual Communication. 2(1), 29-57.

Irvine, J. T. \& Gal, S. (2000). Language ideology and linguistic differentiation. In_P. V. Kroskrity (Ed.), Regimes of language. Ideologies, politics, and identities. (pp. 35-83). Santa Fe, TX: School of American Research Press.

King, K. \& Fogle, L. (2006). Bilingual parenting as good parenting: Parents' perspectives on family language policy for additive bilingualism. International Journal of Bilingual Education and Bilingualism, 9(6), 695-712.

Kramsch, C. (2009). The multilingual subject. Oxford, NY: Oxford University Press.

Kroskrity, P. V. (2000). Regimes of language. Ideologies, politics, and identities. Santa Fe, TX: School of American Research Press.

Lanza, E. (2007). Multilingualism in the family. In P. Auer \& Li Wei (Eds.), Handbook of multilingualism and multilingual communication (pp. 45-67). Berlin, Germany: 
Lefebvre, H. (1991). The production of space. Oxford, UK: Blackwell.

Ma, E. K. (2002). Translocal spatiality. International Journal of Cultural Studies, 5(2), $\underline{131-152 .}$

Massey, D. (2005). For space. London, UK: Sage.

Mayall, B. (2002). Towards a sociology of childhood. Thinking from children's lives. Buckingham, UK: Open University Press.

Norton, B. (2013). Identity and language learning. Extending the conversation. $2^{\text {nd }}$ ed. Bristol, UK: Multilingual Matters.

Pavlenko, A. \& Blackledge, A. (2004). Introduction: New theoretical approaches to the study of negotiation of identities in multilingual contexts. In A. Pavlenko \& A. Blackledge (Eds.)._Negotiation of identities in multilingual contexts_(pp. 1-33). Bristol, UK: Multilingual Matters.

Piller, I. (2002). Bilingual couples talk. The discursive construction of hybridity. Studies in Bilingualism. Amsterdam, The Netherlands: John Benjamins.

Purkarthofer, J. (2016). Sprachort Schule. Zur Konstruktion von mehrsprachigen sozialen Räumen und Praktiken in einer zweisprachigen Volksschule. [School as a space for languages. On the construction of heteroglossic social and spatial practices in a bilingual primary school.] Klagenfurt, Austria: Drava.

Roubeni, S., De Haene, L., Keatley, E., Shah, N. \& Rasmussen, A. (2015). “If we can’t do it, our children will do it one day": A qualitative study of West African immigrant parents' losses and educational aspirations for their children. American Educational Research Journal, 52(2), 275-305.

Schwartz, M. \& Verschik, A. (Eds.) (2013). Successful family language policy: Parents, children and educators in interaction. Dordrecht, The Netherlands: Springer.

Tuan, Y. (1977). Space and place. The perspective of experience. Minneapolis: University of Minnesota Press. 